\title{
What should community mental health workers do? Experience in an inner city support team
}

\author{
T. H. TuRner, Consultant Psychiatrist and Director; A. LoveTt, Co-Director; and \\ M. Ness, Project Officer, Community Psychiatry Research Unit, Hackney Hospital, \\ London E9 6BE
}

\section{Background}

In 1979 a survey of Hackney's psychiatric in-patients revealed that many were resident simply because there was nowhere else for them to go. (Lomas, 1979). As a response to this, the Community Psychiatry Research Unit (CPRU) was set up, and a team of support workers appointed (from nursing, social work and occupational therapy backgrounds) to assist in re-housing and to provide continuing care. Developing projects have meant that the role and job description of this support team have constantly changed. To review their present role, we decided to assess the day-to-day activities of three workers so as to improve our understanding of their function, training needs and work load. Details of the assessment criteria for taking on patients have been outlined by Rich et al (1989).

\section{The study}

After coding their work into three broad areas ('direct' personal contacts, 'indirect' discussions about clients, and 'administrative') three support workers kept a detailed record of what they did each day over four weeks. The information was entered on a day sheet, with details of date, type of event, topic or content of contact, and the time taken. A similar sheet was placed in each client's notes. To qualify for entry an item had to be actively discussed rather than merely mentioned in passing.

\section{Findings}

The time each support worker spent on direct contact $(43 \%)$, indirect contact $(11 \%)$ and general administrative and general liaison work $(20 \%)$ left $26 \%$ of time unrecorded.

\section{Direct contacts}

The total number of direct contacts was 196 and this took up 176 hours of the support workers' time. The bulk $(65 \%)$ of this direct contact was accounted for by home visits, 114 hours for 120 visits, giving an average time of nearly an hour a visit (57 minutes).
The client group made 47 visits to the Unit over four weeks, taking 17 hours 25 minutes $(9.5 \%$ of the time). The 20 pre-arranged visits averaged just over half an hour, whereas the 27 unexpected visits took just under a quarter of an hour per client. Social activities with clients exceeded these contacts, three events totalling 22 hours 45 minutes (13\%), while ward, day-centre and informal contacts completed the remaining hours.

\section{Indirect contacts}

These totalled 46 hours 40 minutes, with 13 formal case reviews (15 hours 15 minutes) taking up some $33 \%$ of the time. Informal and professional contacts with other workers involved 10 hours 55 minutes (1 hour 50 minutes informal discussion; 7 hours 45 minutes discussion with other professionals; 1 hour 20 minutes when other professionals came to the Unit), while 17 'visits' (e.g. Post Office, Housing Department) used another 7 hours 35 minutes. These represented $23 \%$ and $16 \%$ of the time respectively.

Telephone calls to and from other agencies totalled 43 events overall, taking 12 hours 55 minutes support worker time $(28 \%)$. Calls to the Department of Social Security (DSS) lasted 25 minutes on average, while calls to and from others lasted 15 minutes.

\section{Administrative work}

This represented $20 \%$ of the team's available time. It included 15 hours on internal meetings (19\%), eight hours of external meetings $(11 \%)$ and 38 hours 45 minutes on general notes and administration. During the four weeks one support worker had two intensive periods of seven hours training, and two support workers provided five hours of educational training for others.

\section{Content of direct contact with clients}

This was collected under headings listed in Table I. In all, 36 different topics were discussed but mental and physical health, and welfare rights dominated the sessions. 
TABLE I

Breakdown of topics discussed by support workers during direct contact with clients from 13 June to 8 July 1988

\begin{tabular}{|c|c|c|c|}
\hline Topics discussed & Number & of times & Percentage \\
\hline $\begin{array}{l}\text { Health } \\
\text { Mental health } \\
\text { Medication } \\
\text { Hospital appointments etc } \\
\text { Physical health } \\
\text { GP appointments etc } \\
\text { Self-harm } \\
\text { Self-abuse }\end{array}$ & $\left.\begin{array}{r}63 \\
31 \\
20 \\
19 \\
4 \\
2 \\
1\end{array}\right\}$ & 140 & $36 \%$ \\
\hline $\begin{array}{l}\text { Benefits/budgeting etc } \\
\text { DHSS benefits } \\
\text { Housekeeping } \\
\text { Housing } \\
\text { Housing benefit } \\
\text { Post Office visits } \\
\text { Shopping } \\
\text { Transport } \\
\text { Fuel }\end{array}$ & $\left.\begin{array}{r}44 \\
23 \\
10 \\
7 \\
3 \\
2 \\
2 \\
1\end{array}\right\}$ & 92 & $24 \%$ \\
\hline Counselling & & 69 & $18 \%$ \\
\hline $\begin{array}{l}\text { Social Activities } \\
\text { Daytime activities } \\
\text { Social activities } \\
\text { Children } \\
\text { Relatives/friends } \\
\text { Concerned neighbour } \\
\text { Sex }\end{array}$ & $\left.\begin{array}{r}17 \\
17 \\
15 \\
9 \\
3 \\
2\end{array}\right\}$ & 63 & $16 \%$ \\
\hline Crisis & & 11 & $3 \%$ \\
\hline \multirow[t]{2}{*}{ Others } & & 13 & $3 \%$ \\
\hline & & 388 & $100 \%$ \\
\hline
\end{tabular}

\section{Comment}

Twenty-six per cent of the three support workers' time was unaccounted for. Possible explanations include ineffective visits, travel time in a trafficchoked London borough, and retrospective, end-ofthe-day collection of data. Another possibility is that community-orientated workers always have difficulty accounting for every minute of a very flexible and busy day. Their recording may have dealt with major events, leaving out, for instance, the long wait in the Post Office to collect a client's money or time spent in Out-patients after being waylaid to discuss a patient.

The amount of time spent in direct contact was $43 \%$ and a useful question to ask is what proportion of support workers' time should be spent in this way. Is $50 \%$ a reasonable target for direct contact? For any given caseload, what is the optimum amount of direct contact and what time should be devoted to indirect contact and administrative training, or related activities?
Independent living, despite the burden of longterm mental illness (in the majority of cases chronic schizophrenia), requires some degree of health, competence and confidence. That the support team were constantly dealing with their clients' physical and mental well-being on each visit was no surprise. Home visits formed the major part of direct contacts, yet 'psychiatric' issues remained the predominant topic despite these 'domiciliary' surroundings. Factors of illness persist despite 'community care'.

Well-being depends on money for food and access to shelter. Money needs budgeting and homes need upkeep and repairs. These topics were discussed frequently, pointing to the need for expertise in housing matters and benefits entitlement as well as in everyday household budgeting. Witheridge (1989) in a discussion of community support for people with long term mental illness, listed "attending to the concrete details of everyday life" as essential, pointing out that it is the:

". . . seemingly "trivial" activities of daily living that produce some of the most stubborn and critical problems for people with psychiatric disabilities".

Dealing with the DSS was, not surprisingly, an important and time-consuming role. This reflected the complexity of benefit systems and the need for interviewing and personality skills. Sadly, being articulate and diplomatic with saint-like patience and dogged persistence have become key attributes needed to prise out money that should be a vailable as of right.

Outlining the components of clinical case management, Kanter (1989) focused on the physical and social environment and not on housing and entitlements. His list included initial assessment, linking with community resources, maintenance and expansion of social networks, collaboration with physicians and hospitals, advocacy, training in independent living skills, crisis intervention and monitoring-all of which were covered by the support workers in their Direct and Indirect Contacts. Were the government to adopt a clear co-ordinated policy for entitlements for people disabled by long-term mental illness, much DSS and support worker time could be more fruitfully directed.

\section{Conclusions}

This preliminary assessment has been valuable in clarifying the personal tasks required of those working in the front-line of community care. Psychiatric experience, knowledge of the welfare system and communication skills seem essential. The absence of families, and the limited resources of an impoverished inner-city area are factors rarely considered in much community psychiatry research. The skills 
required in these contexts can be deemed much more practical and comprehensive than in other reported scenarios.

\section{References}

KANTER, J. (1989) Clinical case management: definition, principles, components. Hospital \& Community Psychiatry, 40, 361.
Lomas, G. (1979) Long-Term Mental Illness in Hackney. Centre for Environmental Studies Working Note 565.

Ruch, M. et al (1989) Coordinating care for people disabled by long-term mental illness living in the community. Psychiatric Bulletin, 13, 290-291.

WITHRIDGE, T.F.(1989) The assertive community treatment worker: an emerging role and its implications for professional training. Hospital and Community Psychiatry, $40,620$.

\title{
Lunacy, insanity, and the purpose of psychiatry
}

\author{
Bruce G. Charlton, Anatomy Department, University of Glasgow, Glasgow G12 8QQ
}

Insane: Not of sound mind, mad, mentally deranged. Oxford English Dictionary.

Lunatic: Originally, affected with the kind of insanity that was supposed to have recurring periods dependent on the changes of the moon. Oxford English Dictionary.

Madness need not be regarded as an illness. Why shouldn't it be seen as a sudden-more or less sudden-change of character. Wittgenstein, 1980.

Within psychiatry there are two distinct tendencies. On the one hand there is the tendency for the subject to expand beyond its concern with psychological medicine and encroach upon diverse aspects of society. "The psychiatrist who believes that the phenomena of mental illness can be explained on the basis of a universal theory ... finds little difficulty in inflating his theory to explain not only mental disease but also normal human behaviour, interpersonal relations, and ultimately human affairs" (Miller, 1970).

On the other hand there is a countervailing movement which seeks to limit psychiatry, and to contain it within boundaries. Psychiatry should be restricted for reasons which are both moral and practical. The practice of "triage", or discrimination in treatment, is desirable as well as efficient.

Ethical objections relate to the dangerous effects of concepts derived from the study of morbid psychology - "the caricatures of normal human behaviour that present as psychoses or neuroses" (Miller, 1970) - when they are applied beyond what is strictly justified on either therapeutic or forensic grounds. There is not space here to rehearse the arguments against what might be called the "psychiatrisation" of society, except that it is likely to be even worse than the currently excessive state of medicalisation (Woods, 1984).

But the pragmatic case alone seems decisive. Psychiatry is clearly more effective in some of its interventions than others. Common sense would imply that emphasis should be placed on effective actions rather than indefinable or marginal benefits. Therefore, we already have some guidelines towards defining the purpose of the subject.

So far this is relatively uncontroversial: most people would agree with at least the idea of limits and the notion of doing what one is good at. The difficulties begin when we try to decide how limits should be established and upon what principles they should be based. Because cases are frequently unclear, the boundary at which intervention should be attempted is blurred, and the conflict between opposing moral principles may become acute.

The reason would seem to lie in the fact that psychiatry has historically developed with two distinct purposes which, although they overlap, may at times contradict each other. I have chosen the names Lunacy and Insanity for the objects of these purposes, because the terms capture something of the contrast within the subject - but I could equally well have chosen Therapeutics and Forensics which puts the matter in a similar perspective.

Psychiatry can regard the behaviour of a given person in two contexts: that of the subject's own 